\title{
Residents focus on fatigue management
}

$\mathrm{M}$

ost industries would flinch at the idea of their staff working 24 continuous hours, but the practice is common for junior doctors in Canada. Regulating duty hours has traditionally been a key factor in discussions on resident wellness and patient safety, but the conversation has shifted to fatigue management.

A fatigue risk management task force, composed of representatives from all sectors of Canadian postgraduate medical education, is now fully operational and helping to implement fatigue management strategies into residency training programs. The task force was created after the National Steering Committee on Resident Duty Hours chose not to endorse a onesize-fits-all cap on duty hours in their 2013 final report.

"The conversation has changed to fatigue management and how overall to best equip residents and staff physicians to manage their fatigue. So residency hours are a part of that, but it's just that, a part," says task force cochair Dr. Tom McLaughlin, president of Resident Doctors of Canada (RDoC)

Quebec is the only province where resident duty hours are capped (at 16 hours). RDoC, which represents residents outside Quebec, does not plan to endorse a similar reduction in duty hours. "I think that's a simplistic answer to a complex problem," says McLaughlin.

Focusing solely on duty hours is problematic partly because studies have not shown any improvement in patient safety with shorter duty hours. "Do attempts at reducing duty hours improve patient safety? Absolutely not, under any circumstances," says Dr. Kevin Imrie, co-chair of the task force and president of the Royal College of

As concluded in the steering committee's 2013 report, duty hours are only one component of managing fatigue. According to the report, a comprehensive approach to fatigue management would require every institution to perform regular assessments of workload intensity and risk assessments of residents to ensure they are fit to work. Mental health crisis response programs should be available to trainees. Educational programs promoting wellness within the workplace and selfawareness of one's fitness to practise would also be required.

In Quebec, the hard cap on duty hours does not appear to have had a negative impact on resident training, according to Dr. Armand Aalamian, associate dean of postgraduate

Physicians and Surgeons of Canada.

$\mathrm{He}$ cites an abundance of trials that have compared shorter duty hours to standard practices and most don't show any differences in patient safety or resident satisfaction. The largest of these trials was recently published in the New England Journal of Medicine. The study randomly assigned more than 4000 surgery residents to either standard duty hours or a flexible system with no limit on work hours, and did not reveal any differences in patient death or resident fatigue. A similar large-scale trial for internal medicine residents is currently recruiting participants. Other studies have reported similar findings, including a $C M A J$ paper involving intensive care unit residents in Canada.

Although there is no clear evidence directly linking fatigue to medical errors, there is evidence, however, suggesting it can impair the cognitive performance of residents. medical education at McGill University. "We do continue tracking the performance of our residents at all our core universities and faculties of medicines to make sure that their learning objectives are being met," he says. "And we don't have, to date, any indication that there are any concerns with this change of working hours schedule."

Resident associations in Quebec have not collected data on resident satisfaction since the transition. "No one's thinking about bringing back 24-hour call," says Dr. Aris Hadjinicolaou, president of the Association of Residents of McGill. The latest collective agreement submitted to the government by Quebec residents made no mention of changing resident duty hours. Fatigue management, however, continues to be an issue that the resident associations hope to address. Wilson Kwong, Toronto, Ont.

CMAJ 2016. DOI:10.1503/cmaj.109-5275 